\title{
Brain Bilirubin Deposition and Brain Blood Flow during Acute Urea-Induced Hyperosmolality in Newborn Piglets ${ }^{1}$
}

\author{
GARY H. BURGESS, BARBARA S. STONESTREET, WILLIAM J. CASHORE, AND WILLIAM OH \\ Department of Pediatrics, Women and Infants Hospital of Rhode Island and Brown University Program in \\ Medicine, Providence, Rhode Island 02908
}

\begin{abstract}
Acute hyperosmolality-induced blood brain barrier breakdown has been demonstrated to increase the permeability of sucrose, which is similar in molecular weight to bilirubin, independently of changes in regional brain blood flow. We studied three groups of piglets given continuous bilirubin infusions to maintain serum bilirubin concentrations at approximately $8 \mathrm{mg} / \mathrm{dl}$. Normal serum osmolality was maintained throughout the study in control animals. Two experimental groups were made hyperosmolar (330 and $375 \mathrm{mosmol} / \mathrm{liter}$ ) with bolus urea infusions during the last hour of the study. Regional brain bilirubin concentrations were elevated in the 375 mosmol/liter hyperosmolal experimental group, but not in the $330 \mathrm{mosmol} /$ liter group. Regional brain albumin concentrations also were increased over the control group in the $375 \mathrm{mosmol} /$ liter animals. There were no differences in regional brain blood flows to account for the increases in brain bilirubin concentrations. Our results show that brain bilirubin deposition occurs following breakdown of the blood brain barrier by acute, severe hyperosmolality $(375 \mathrm{mosmol} /$ liter) and that the deposited bilirubin is derived from both bound and unbound fractions. The bilirubin deposition occurs independently of changes in regional brain blood flow; however, regional differences in the blood brain barrier permeability to albumin also occur. (Pediatr Res 19: $537-542,1985$ )
\end{abstract}

Acutely induced serum hyperosmolality has been demonstrated to break down the blood brain barrier in several animal species (1). The associated shrinkage of brain capillary endothelial cells results in the opening of tight junctions. The size of the "pores" thus produced probably is related to the osmotic gradient between the intravascular space and the brain interstitium (2). Regional differences in the osmotic opening of the blood brain barrier have been reported in rats; the gray matter in the thalamic and hypothalamic regions was most affected. The permeability of these regions to sucrose was independent of regional brainblood flow (3).

Acute urea-induced hyperosmolality has been demonstrated

Received July 9, 1984; accepted January 30, 1985.

Address for reprints William Oh, M.D., Women and Infants Hospital of Rhode Island, Department of Pediatrics, 50 Maude Street, Providence, RI 02908.

Supported in part by Training Grant 1232-HD-07232, National Institute of Child Health and Human Development, Bethesda, MD.

${ }^{1}$ This study was presented in part at the combined 94th Annual Meeting of the American Pediatric Society and the 53rd Annual Meeting of the Society for Pediatric Research in San Francisco, CA, May 3, 1984; and published in abstract form 1984 Pediatr Res 18:314A. in rats to cause a transient increase in cerebral blood flow followed by a transient decrease which persisted for approximately $1 \mathrm{~h}$ (4). The initial blood flow increase was suggested to be due to the direct dilating effect of urea on the brain arterioles (5); the cause for the rebound decrease in blood flow remains obscure.

We demonstrated that the midbrain and cerebellar regions of the brain of hypercapnic piglets contained more bilirubin than normocapnic control piglets (6). The increased bilirubin was not associated with increased brain albumin suggesting that the blood brain barrier was intact to albumin during hypercapnia. Regional differences in brain bilirubin deposition were demonstrated during hypercapnia, the subcortical regions (the midbrain, cerebellum, and brainstem) having greater bilirubin concentrations than the cortical regions. Rat brains have been shown to develop diffuse yellow staining, following arabinose-induced hyperosmolality (7). We have shown that both rat brain albumin and bilirubin concentrations were increased following urea-induced hyperosmolality. Both brain albumin and bilirubin were related to the serum osmolality with marked increases found above 340 mosmol/liter (8).

The present study was conducted to assess whether both bound and unbound bilirubin enter the brain and whether the brain bilirubin deposition is related to regional brain blood flow following urea-induced hyperosmolality.

\section{MATERIALS AND METHODS}

Thirty 2- to 4-day-old farm bred piglets were divided into three study groups: a control group $(n=14$, weight $=1.40 \pm 0.09 \mathrm{~kg}$ mean \pm SEM) in which normal osmolality was maintained throughout the study and two experimental groups in which hyperosmolality was induced with urea infusion during the last hour of study. We previously reported results in the control group as comparative information to evaluate the effect of hypercapnia-induced brain hyperperfusion and brain bilirubin deposition (6). The serum osmolality in the first experimental group (E1 piglets, $n=7$, weight $=1.43 \pm 0.13 \mathrm{~kg}$, mean $\pm \mathrm{SEM}$ ) was increased to approximately $330 \mathrm{mosmol} /$ liter during the last hour of study; that of the second experimental group (E2 piglets, $n=9$, weight $=1.31 \pm 0.09 \mathrm{~kg}$, mean \pm SEM) was increased to approximately 375 mosmol/liter. We performed brain blood flow measurements in six control piglets and did not perform measurements in eight. We have shown that microsphere injections have no effect on regional brain bilirubin content (6). Therefore the two subgroups within the control group were combined for data analysis.

Each piglet was removed from its sow on the morning of study. Surgical procedures were performed under nitrous oxide inhala- 
tion and local $1 \%$ xylocaine anesthesia. The left ventricle was catheterized via the right brachial artery for radionuclide-labeled microsphere injections using a Sentinel line catheter (inside diameter $0.67 \mathrm{~mm}$, outside diameter $1.05 \mathrm{~mm}$, Argyle, St. Louis, $\mathrm{MO}$ ); the placement was verified with pressure tracings and by autopsy. Polyvinyl catheters (inside diameter $0.58 \mathrm{~mm}$, outside diameter $0.99 \mathrm{~mm}$, Bolab, Lake Havasu City, AZ) also were inserted into the following vessels: 1) left brachial artery for microsphere reference blood withdrawal, 2) abdominal aorta via the right femoral artery for monitoring heart rate and mean arterial blood pressure, and 3) the inferior vena cava via the right femoral vein for bilirubin and $I^{125}$-labeled albumin infusions. The left common carotid artery was surgically exposed and two strands of 2-0 silk surgical sutures were loosely placed behind the artery to allow for rapid access at the termination of the study for in situ brain perfusion. Each piglet was removed from the nitrous oxide and placed in a specially designed, darkened box for the study which permitted access to the catheters without disturbing the piglet.

Following a 1-h period for stabilization after surgery, baseline determinations were made on the awake, unrestrained piglets. Each was given a 1 -min bolus infusion of $12 \mathrm{mg} / \mathrm{kg}$ body weight of unconjugated bilirubin (from bovine gallstones, Sigma Chemical Corporation, St. Louis, MO) dissolved in $5.4 \mathrm{ml}$ of a buffered solution of $18.5 \% \mathrm{v} / \mathrm{v}$ of $0.1 \mathrm{~N} \mathrm{NaOH}, 44.5 \%$ of $5 \%$-human serum albumin (Armour Pharmaceutical Company, Kankakee, IL), and $37 \%$ of $0.055 \mathrm{M}$ phosphate buffer. The bilirubin was first dissolved in the $0.1 \mathrm{~N} \mathrm{NaOH}$ to which the albumin and phosphate buffer solutions were then added. This solution had been used in our laboratory for bilirubin studies in rats (8). An infusion of $10 \mathrm{mg}$ bilirubin $/ \mathrm{kg} / \mathrm{h}(167 \mathrm{mg} / \mathrm{dl}$ solution $)$ then was begun and continued for $3 \mathrm{~h}$. This bilirubin dose maintained the serum bilirubin at approximately $8 \mathrm{mg} / \mathrm{dl}$.

During the study, each control piglet was awake and remained in an enclosed box breathing room air which was provided through portholes in the box walls. In both experimental groups, the piglets were made hyperosmotic during the last hour of the study with a 2-min infusion of a urea-water solution $(1 \mathrm{~g} / \mathrm{ml})$; group E1 animals received $4.5 \mathrm{~g} / \mathrm{kg}$ of urea while group E2 received $9.0 \mathrm{~g} / \mathrm{kg}$. Regional brain blood flow was determined at baseline, and at 120 (before hyperosmolality), 150, and $180 \mathrm{~min}$ of the study period. Regional brain blood flow was measured using the technique described by Heymann et al. (10) with $15 \pm$ $5 \mu \mathrm{m}$ diameter microspheres labeled with one of the following radionuclides: ${ }^{103} \mathrm{Ru},{ }^{57} \mathrm{Co},{ }^{113} \mathrm{Sn},{ }^{46} \mathrm{Sc},{ }^{51} \mathrm{Cr}$, or ${ }^{95} \mathrm{Nb}$ (New England Nuclear, Boston, MA). Approximately $6 \times 10^{5}$ microspheres, suspended and continuously agitated in $2 \mathrm{ml}$ of $10 \%$ dextran and $0.01 \%$ Tween, were injected within $30 \mathrm{~s}$ into the left ventricle and flushed with $2 \mathrm{ml}$ of normal saline. A reference sample of blood was collected continuously for 2 min beginning $15 \mathrm{~s}$ prior to the microsphere injection; the blood was withdrawn using a constant withdrawal pump (Harvard Apparatus no. 940, Millis, MA) at a rate of $1.03 \mathrm{ml} / \mathrm{min}$. Blood losses were replaced with blood from a young donor piglet. Arterial blood gases (Corning Blood Gas Analyzer 175, Corning Scientific, Medford, MA) were monitored at the baseline period and at $60,120,140$, 160 , and $180 \mathrm{~min}$ following the onset of the bilirubin infusion. Mean arterial blood pressure and heart rate were continuously monitored using a pressure transducer (Hewlett-Packard 1280c, Waltham, MA) and were recorded on a polygraph (HewlettPackard 7754A). Hematocrit levels were determined using a microhematocrit method.

At the termination of each study, each piglet was anesthetized with nitrous oxide and local $1 \%$ xylocaine in preparation for left carotid artery catheterization with polyvinyl tubing (inside diameter $0.86 \mathrm{~mm}$, outside diameter $1.32 \mathrm{~mm}$, Bolab). The animal was then sacrificed with intravenous sodium thiamylal followed by a solution of saturated potassium chloride. The brain was perfused in situ via the carotid artery with ice-cold normal saline for $15 \mathrm{~min}$ at a pressure of $60 \mathrm{~mm} \mathrm{Hg}$ in order to remove blood from the brain vasculature (and therefore intravascular bilirubin) and to reduce the possible breakdown of extravascular bilirubin by tissue bilirubin oxidases (9). In order to facilitate the perfusion, the superior vena cava was incised and the descending aorta was clamped to decrease the retrograde flow around the circle of Willis and down the contralateral carotid artery. An autopsy was then performed to verify catheter placement and for removal of the brain. The brain was separated from the spinal cord at the level of the first cervical vertebra, divided into right and left hemispheres, and weighed. The left hemisphere was cut into approximately $1 \mathrm{-g}$ sections representing the following brain regions: brain stem, cerebellum, midbrain, thalamus plus caudate nucleus, and cerebrum (four representative sections of cerebrum taken: frontal lobe, occipital lobe, temporal lobe, and parietal lobe). The sections from the left hemisphere were immediately weighed and placed on ice. These sections were assayed within 3 $\mathrm{h}$ of the termination of the study for tissue bilirubin using a modified diazo method following chloroform extraction (11). The bilirubin concentration was determined by multiplying the optical density readings by the slope of a standard curve (in which the 0 -mg bilirubin brain sample was set at an optical density of zero) and divided by the weight in grams of the brain sample. The standard curve was repeated four times, using piglet brain samples weighing approximately $1 \mathrm{~g}$ each (approximately the same size as the piglet brain samples used for the study); the known bilirubin amounts added for the standard curve were 0 , $0.5,1.0,2.0,4.0,6.0$, and $8.0 \mathrm{mg}$.

The right hemisphere was anatomically divided in exactly the same manner as the left and placed into counting vials to an approximate height of $1 \mathrm{~cm}$. Radioactivity of these tissues and of the reference blood samples were measured in a gamma well counter (Packard Auto Gamma Scintillation Spectrometer, Packard Instruments, Downers Grove, IL). All tissues and blood samples contained a minimum of 400 microspheres. The regional brain blood flow data were calculated, using a computer (PdP-11/34 Digital Equipment Corporation, Maynard, MA) to correct for spillovers, according to the formula:

brain-blood flow $(\mathrm{ml} / \mathrm{min})$

$=\frac{\mathrm{cpm} \text { of microspheres in the brain tissue }}{\mathrm{cpm} \text { of microspheres in the reference blood }}$

$\times$ rate of withdrawal $(\mathrm{ml} / \mathrm{min})$.

All values for brain blood flow were expressed as $\mathrm{ml} \cdot \mathrm{min} \cdot{ }^{-1} 100$ $\mathrm{g}^{-1}$.

Total serum bilirubin was measured by Martinek's (12) modification of the diazo method of Malloy and Evelyn. Serum unbound bilirubin was estimated by the peroxidase method (13). Colorimetric determinations were performed on a single beam spectrophotometer (Gilford model 240, Oberlin, OH) and where appropriate were recorded on an automatic recorder (Gilford model 6051). Serum osmolality was determined with a vapor pressure osmometer (Wescor, Inc., Logan, UT). Regional brain albumin content was measured in the experimental piglets and in a separate group of six control piglets (treated with exactly the same study protocol except regional brain blood flow measurements were not determined). All piglets received an intravenous infusion of $50 \mu \mathrm{Ci}$ of $\mathrm{I}^{125}$-bovine serum albumin (New England Nuclear, Boston, MA) just prior to the bilirubin bolus injection. At the termination of the study, serum was obtained for $\mathrm{I}^{125}$ radioactivity. The serum albumin concentration at 180 -min also was determined using the bromcresol green spectrophotometric method (14). The albumin concentrations of eight sections of the right brain hemisphere were determined using the specific activity of serum albumin and the $I^{125}$-radioactivity of the brain tissue.

To determine the effect of urea on albumin-binding of bilirubin, serum was obtained from three newborn piglets devoid of bilirubin. Each of the piglet's serum samples was divided into 
four subsamples; two with no urea and two in which $10 \mathrm{~g} / 100$ $\mathrm{ml}$ urea was added. To all samples $8 \mathrm{mg} / 100 \mathrm{ml}$ of unconjugated bilirubin (Sigma Chemical Corp.) were added. Serum unbound bilirubin was calculated using the peroxidase method (13) in exactly the same manner as the study piglet's sera. In the ureafree sample, the mean serum unbound bilirubin was found to be $688 \mathrm{nmol} /$ liter, when the total serum bilirubin was $8 \mathrm{mg} / 100$ $\mathrm{ml}$. In the sera to which $10 \mathrm{~g} / 100 \mathrm{ml}$ urea were added, the mean serum unbound bilirubin was $1048 \mathrm{nmol} /$ liter when the total serum bilirubin was $8 \mathrm{mg} / 100 \mathrm{ml}$.

Within group data were compared using the analysis of variance for repetitive measures. Where a significant difference was found, Dunnett's multiple range $t$ test was used to compare the means to the baseline values (15). Within group regional brain differences were analyzed using analysis of variance and the Newman-Keuls multiple comparison test. Between group analysis was done using the unpaired Student's $t$ test. Repetitive measurements were compared between groups, using the Bonferroni adjustment (16). Unless otherwise stated, a $p<0.05$ was considered statistically significant. All values were expressed as mean \pm SEM

\section{RESULTS}

The hemodynamic data including arterial blood gas, heart rate, mean arterial blood pressure, and hematocrit during the 3$\mathrm{h}$ study in the three groups are summarized in Table 1 . Small decreases in $\mathrm{pH}$ were noted in both experimental groups during the hyperosmolal period. These decreases in $\mathrm{pH}$ were associated with small, but significant increases in $\mathrm{PACO}_{2}$ values. $\mathrm{PAO}_{2}$ and base excess values remained stable in all groups during the study period. Heart rate, mean arterial blood pressure, and hematocrit values remained stable in the control and E1 groups. In the E2 group, heart rate values were lower throughout the entire study; the mean arterial blood pressure values during the hyperosmolal period, although not significantly different from the control group values, were elevated significantly above the baseline values. Hematocrit values were similar for the control and E1 groups, but were slightly but significantly increased in the E2 group during most of the 3-h study.

Serum osmolality, albumin, total bilirubin, and unbound bilirubin values are summarized in Table 2 . Serum osmolality remained stable throughout the 3-h study period in control animals. During the hyperosmolal period in both experimental groups, sustained increases in serum osmolality were seen (approximately 330 mosmol of liter in El and 375 mosmol of liter in E2). Slight increases of serum albumin values above baseline were observed in all groups, with peak values of approximately $1.6 \mathrm{~g} / \mathrm{dl}$ obtained at $180 \mathrm{~min}$. serum total bilirubin values remained stable in the $6-10 \mathrm{mg} / \mathrm{dl}$ range during the last hour of study in all groups. In E2 animals, the serum unbound bilirubin levels were 2 -fold higher than control values during the entire study period following the baseline determinations. During the last hour of study, serum unbound bilirubin levels stabilized at $300-450 \mathrm{nmol} / \mathrm{liter}$ for the control and E1 groups and $815 \mathrm{nmol} /$ liter for E2.

Table 1. Hemodynamic values (mean \pm SEM)

\begin{tabular}{|c|c|c|c|c|c|c|c|c|}
\hline \multirow[b]{3}{*}{ Time $(\min )$} & & \multirow[b]{3}{*}{ Baseline } & \multicolumn{6}{|c|}{ Hyperosmolality (E1 and E2 only) } \\
\hline & & & \multicolumn{6}{|c|}{ Bilirubin infusion } \\
\hline & & & 60 & 120 & 140 & 150 & 160 & 180 \\
\hline \multirow[t]{3}{*}{$\mathrm{pH}$} & $\mathrm{C}^{*}$ & $7.47 \pm 0.01$ & $7.49 \pm 0.01$ & $7.50 \pm 0.01 \dagger$ & $7.50 \pm 0.01 \dagger$ & ND\$ & $7.49 \pm 0.01$ & $7.49 \pm 0.01 \dagger(13)$ \\
\hline & E1 & $7.47 \pm 0.03$ & $7.45 \pm 0.02$ & $7.47 \pm 0.02$ & $7.43 \pm 0.01 \uparrow \S$ & ND & $7.41 \pm 0.01 \uparrow \S$ & $7.42 \pm 0.01 \dagger \S$ \\
\hline & E2 & $7.46 \pm 0.01$ & $7.46 \pm 0.01(8)$ & $7.47 \pm 0.02$ & $7.37 \pm 0.02 \dagger \S(8)$ & ND & $7.38 \pm 0.02+\S(8)$ & $7.40 \pm 0.02 \uparrow \S$ \\
\hline \multirow{3}{*}{$\begin{array}{c}\mathrm{PACO}_{2}(\mathrm{~mm} \\
\mathrm{Hg})\end{array}$} & $\mathrm{C}$ & $35 \pm 1$ & $33 \pm 1$ & $32 \pm 1 \dagger$ & $33 \pm 1$ & ND & $32 \pm 1 \dagger$ & $33 \pm 1(13)$ \\
\hline & E1 & $32 \pm 2$ & $34 \pm 1$ & $33 \pm 1$ & $35 \pm 1$ & ND & $38 \pm 1 \dagger \S$ & $38 \pm 2+\S$ \\
\hline & E2 & $37 \pm 1$ & $39 \pm 1 \S(8)$ & $37 \pm 1 \S$ & $44 \pm 2+\S(8)$ & ND & $43 \pm 2+\S(8)$ & $45 \pm 3+\S$ \\
\hline \multirow{3}{*}{$\begin{array}{c}\mathrm{PAO}_{2}(\mathrm{~mm} \\
\mathrm{Hg})\end{array}$} & $\mathrm{C}$ & $75 \pm 3(13)$ & $75 \pm 3(13)$ & $73 \pm 4$ & $74 \pm 3$ & ND & $72 \pm 2$ & $71 \pm 3(13)$ \\
\hline & E1 & $78 \pm 7$ & $86 \pm 14(6)$ & $70 \pm 6$ & $66 \pm 4$ & ND & $66 \pm 4$ & $66 \pm 4$ \\
\hline & E2 & $83 \pm 4$ & $81 \pm 5(8)$ & $79 \pm 4$ & $65 \pm 3 \dagger(8)$ & ND & $70 \pm 3 \dagger(8)$ & $70 \pm 4 \dagger$ \\
\hline \multirow{3}{*}{$\begin{array}{l}\text { Base excess } \\
\quad(\mathrm{mEq} / \mathrm{li}- \\
\text { ter) }\end{array}$} & $\mathrm{C}$ & $3 \pm 1$ & $3 \pm 1$ & $3 \pm 1$ & $3 \pm 1$ & ND & $2 \pm 1$ & $3 \pm 1(13)$ \\
\hline & E1 & $2 \pm 2$ & $1 \pm 2$ & $2 \pm 1$ & $0 \pm 1 \S$ & ND & $0 \pm 1$ & $1 \pm 1$ \\
\hline & $\mathrm{E} 2$ & $3 \pm 1$ & $4 \pm 1(8)$ & $4 \pm 1(8)$ & $0 \pm 1 \dagger(8)$ & ND & $1 \pm 1 \dagger(8)$ & $3 \pm 1$ \\
\hline \multirow{3}{*}{$\begin{array}{l}\text { Heart rate } \\
\text { (beats/ } \\
\text { min) }\end{array}$} & $\mathrm{C}$ & $198 \pm 10(13)$ & $196 \pm 7(12)$ & $209 \pm 7(13)$ & $207 \pm 8(13)$ & $210 \pm 7(13)$ & $215 \pm 9(13) \dagger$ & $221 \pm 8(13)$ \\
\hline & E1 & $204 \pm 22$ & $210 \pm 21$ & $203 \pm 19$ & $197 \pm 19$ & $205 \pm 22$ & $203 \pm 20$ & $198 \pm 18$ \\
\hline & E2 & $161 \pm 14$ & $180 \pm 15$ & $198 \pm 12(8) \dagger$ & $162 \pm 14$ & $175 \pm 19(8)$ & $169 \pm 17$ & $162 \pm 13 \S$ \\
\hline \multirow{3}{*}{$\begin{array}{l}\text { Mean arte- } \\
\text { rial blood } \\
\text { pressure } \\
(\mathrm{mm} \mathrm{Hg})\end{array}$} & C & $69 \pm 3(12)$ & $66 \pm 3(12)$ & $69 \pm 3(12)$ & $68 \pm 3(12)$ & $71 \pm 3(12)$ & $72 \pm 3(12)$ & $66 \pm 3(12)$ \\
\hline & El & $70 \pm 3$ & $68 \pm 3$ & $69 \pm 3$ & $79 \pm 4 \dagger$ & $83 \pm 5 \dagger$ & $78 \pm 4$ & $77 \pm 4$ \\
\hline & E2 & $59 \pm 3$ & $63 \pm 3$ & $69 \pm 3 \dagger$ & $78 \pm 3 \dagger$ & $75 \pm 2 \dagger$ & $83 \pm 5 \dagger(8)$ & $80 \pm 6 \dagger$ \\
\hline \multirow{3}{*}{$\begin{array}{l}\text { Hematocrit } \\
(\%)\end{array}$} & $\mathrm{C}$ & $24 \pm 1$ & $23 \pm 1$ & $22 \pm 1 \uparrow$ & ND & ND & ND & $22 \pm 1 \dagger(12)$ \\
\hline & E1 & $27 \pm 3$ & $26 \pm 2(6)$ & $26 \pm 2$ & ND & ND & ND & $25 \pm 1$ \\
\hline & E2 & $26 \pm 2$ & $26 \pm 1 \S$ & $27 \pm 1 \S$ & ND & ND & ND & $28 \pm 2 \S$ \\
\hline
\end{tabular}

* C, control group, $n=14$ unless otherwise noted in parentheses; $\mathrm{E} 1$, experimental group with osmolality approximately $330 \mathrm{mosmol} / \mathrm{liter}, n=$ 7 unless otherwise noted in parentheses; E2, experimental group with osmolality approximately 375 mosmol/liter, $n=9$ unless otherwise noted in parentheses.

$\dagger p<0.05$ compared to control.

$\ddagger$ Not determined.

$\S p<0.05$ compared to baseline. 
Table 2. Serum osmolality, albumin, total and unbound bilirubin (mean \pm SEM)

\begin{tabular}{|c|c|c|c|c|c|c|c|c|}
\hline \multirow[b]{3}{*}{ Time $(\min )$} & & \multirow[b]{3}{*}{ Baseline } & \multicolumn{6}{|c|}{ Hyperosmolality (E1 and E2 only) } \\
\hline & & & \multicolumn{6}{|c|}{ Bilirubin infusion } \\
\hline & & & 60 & 120 & 140 & 150 & 160 & 180 \\
\hline \multirow{3}{*}{$\begin{array}{l}\text { Serum osmolality } \\
\text { (mosmol/liter) }\end{array}$} & $\mathrm{C}^{*}$ & $288 \pm 2$ & $288 \pm 2$ & $283 \pm 1 \dagger$ & ND $\ddagger$ & $285 \pm 1$ & ND & $284 \pm 1 \dagger$ \\
\hline & E1 & $282 \pm 4$ & $283 \pm 3$ & $284 \pm 2$ & ND & $331 \pm 3 \uparrow \S$ & ND & $328 \pm 2 \uparrow \S$ \\
\hline & $\mathrm{E} 2$ & $286 \pm 3$ & $285 \pm 3$ & $285 \pm 3$ & ND & $376 \pm 4 \uparrow \S$ & ND & $375 \pm 4 \uparrow \S$ \\
\hline \multirow[t]{3}{*}{ Serum albumin $(\mathrm{g} / \mathrm{dl})$} & $\mathrm{C}$ & $1.4 \pm 0.1$ & $1.5 \pm 0.1$ & $1.6 \pm 0.1 \dagger$ & ND & $1.7 \pm 0.1 \dagger$ & ND & $1.7 \pm 0.1 \dagger$ \\
\hline & E1 & $1.3 \pm 0.1$ & $1.3 \pm 0.1$ & $1.5 \pm 0.1$ & ND & $1.5 \pm 0.2$ & ND & $1.6 \pm 0.1 \dagger$ \\
\hline & E2 & $1.0 \pm 0.2$ & $1.2 \pm 0.2 \dagger$ & $1.4 \pm 0.2 \dagger$ & ND & $1.4 \pm 0.2 \dagger$ & ND & $1.6 \pm 0.2 \dagger$ \\
\hline \multirow{3}{*}{$\begin{array}{l}\text { Total serum bilirubin } \\
(\mathrm{mg} / \mathrm{dl})\end{array}$} & $\mathrm{C}$ & $1.6 \pm 0.3$ & $6.9 \pm 0.3 \dagger$ & $7.9 \pm 0.3 \dagger$ & ND & $8.6 \pm 0.5 \dagger$ & ND & $9.4 \pm 0.4 \dagger$ \\
\hline & E1 & $0.4 \pm 0.2$ & $4.5 \pm 0.5 † \S$ & $5.7 \pm 0.7 \uparrow \S$ & ND & $6.5 \pm 0.7 \dagger$ & ND & $7.2 \pm 0.6 \dagger \S$ \\
\hline & E2 & $0.1 \pm 0.06 \S$ & $5.9 \pm 0.7 \dagger$ & $7.8 \pm 0.9 \dagger$ & ND & $8.0 \pm 0.9 \dagger$ & ND & $10.0 \pm 1.1 \dagger$ \\
\hline \multirow{3}{*}{$\begin{array}{l}\text { Serum unbound bili- } \\
\text { rubin (nmol/liter) }\end{array}$} & $\mathrm{C}$ & undetectable & $205 \pm 28 \dagger$ & $205 \pm 31 \uparrow$ & ND & $377 \pm 53 \dagger(13)$ & ND & $307 \pm 43 \dagger(13)$ \\
\hline & E1 & undetectable & $208 \pm 27 \dagger$ & $213 \pm 52 \dagger$ & ND & $445 \pm 91 \dagger$ & ND & $365 \pm 67 \dagger$ \\
\hline & $\mathrm{E} 2$ & undetectable & $378 \pm 105 \dagger$ & $467 \pm 143 \dagger$ & ND & $804 \pm 122+\S$ & ND & $815 \pm 124+\S$ \\
\hline
\end{tabular}

${ }^{*} \mathrm{C}$, control group, $n=14$ unless otherwise noted in parentheses; E1, experimental group with osmolality approx. 330 mosmol/liter, $n=7 ; \mathrm{E} 2$, experimental group with osmolality approx. $375 \mathrm{mosmol} / \mathrm{liter}, n=9$.

$\dagger p<0.05$ compared to baseline within the same group.

$\$$ Not determined.

$\S p<0.05$ compared to control.

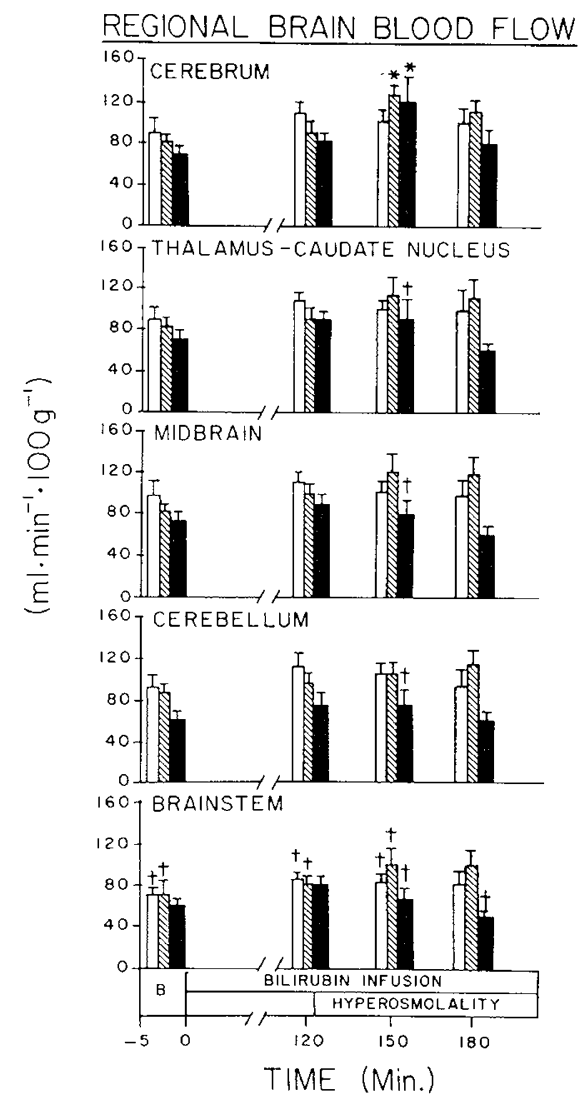

Fig. 1. Regional brain blood flow versus time. Control group (open bar, $n=6$ ), experimental group $\mathrm{E} 1$ ( hatched bar, $n=7$ ), and experimental group E2 (closed bar, $n=7$ ). All values are expressed as mean \pm SEM. ${ }^{*} p<0.05$ as compared to baseline within the same group. $\dagger p<0.05$ as compared to the cerebrum value within the same group at the same time period.

Regional brain blood flows for each brain region during the study period are illustrated in Figure 1. Brain blood flows to all regions were unchanged in the control group. In the control and E1 groups the brain stem demonstrated significantly lower blood flow than the cerebrum at baseline and at the 120- and 150-min determinations. In both experimental groups, the blood flows to the cerebrum at $150 \mathrm{~min}$ were higher than baseline $(120$ versus $75 \mathrm{ml} \cdot \mathrm{min}^{-1} \cdot 100 \mathrm{~g}^{-1}$ ).

Figure 2 shows the regional brain bilirubin concentration data. Brain stem bilirubin was significantly higher than the cerebrum level in the control and E1 groups. Mild hyperosmolality (E1 group) did not alter bilirubin concentrations in any brain region. However, in the higher hyperosmolality group (E2), the brain bilirubin levels were elevated 3 -fold in all regions as compared to control animals.

Figure 3 summarizes the regional brain albumin concentration data. There were no statistically significant differences among regions in the control animals. With mild hyperosmolality (group E1) the albumin concentrations were significantly increased over control values in the cerebrum, thalamus plus caudate nucleus, and midbrain regions. In the higher hyperosmolal state (group E2), the brain albumin concentration was significantly increased in all regions as compared to the control values. In the E2 animals the thalamus, midbrain, and brain stem albumin concentrations were significantly less than values in the cerebrum.

All piglets tolerated the urea infusion without signs of morbidity (ie, seizures, lethargy, etc.). Autopsy examination of the piglets' brains revealed no gross abnormalities except in group E2 animals, in which multiple petechiae were noted along the walls of the lateral ventricles in all of the piglets. Histologic examinations were not performed.

\section{DISCUSSION}

We previously demonstrated that the piglet is useful in studies of brain bilirubin deposition (6) and that radionuclide-labeled microspheres in the dose used in this study do not alter the brain bilirubin deposition (6). Moreover, the bilirubin binding characteristics of piglet albumin resemble those of human serum albumin; approximately $1.3 \mathrm{~mol}$ of bilirubin bind with high affinity to $1.0 \mathrm{~mol}$ of piglet albumin.

During the period of hyperosmolality small changes were noted in the acid-base status of the piglets. While these changes were within the normal physiologic range for newborn piglets in our laboratory (17), they may reflect fluid shifts which occur following the urea infusion. Although we did not measure the blood volume response to urea in this study, we speculate that a rapid 


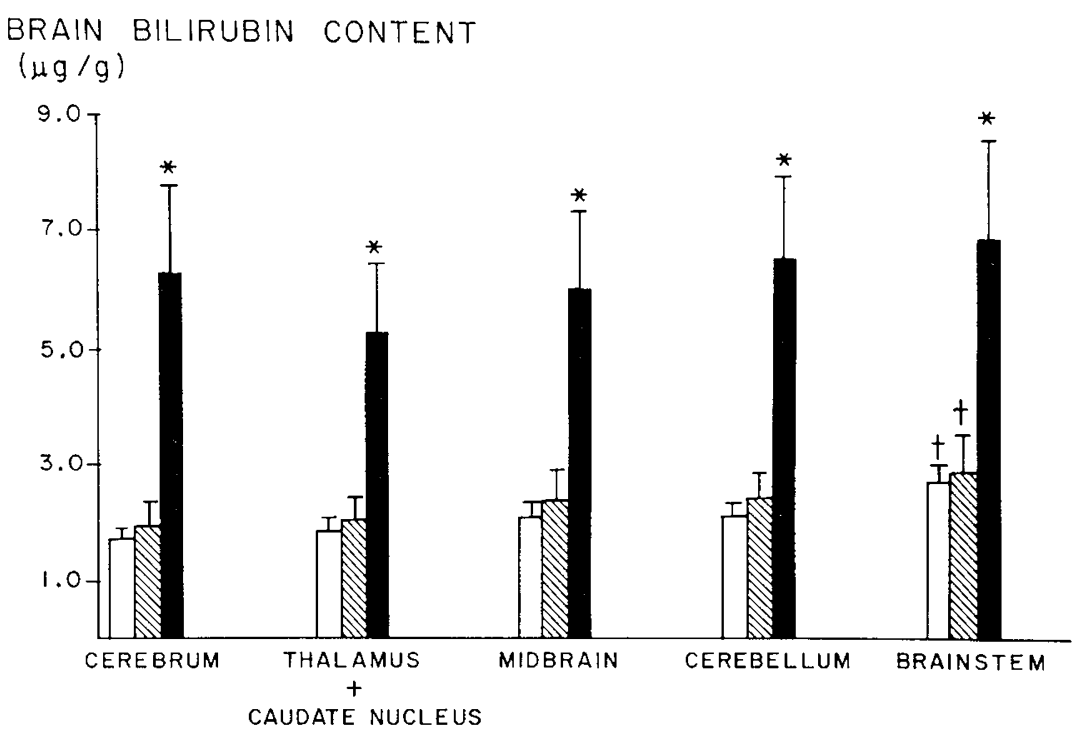

BRAIN REGIONS

Fig. 2. Regional brain bilirubin content. Group legends are the same as in Figure 1. All values are expressed as mean \pm SEM. $+p<0.05$ as compared to the cerebrum value within the same group. ${ }^{*} p<0.05$ as compared to control.

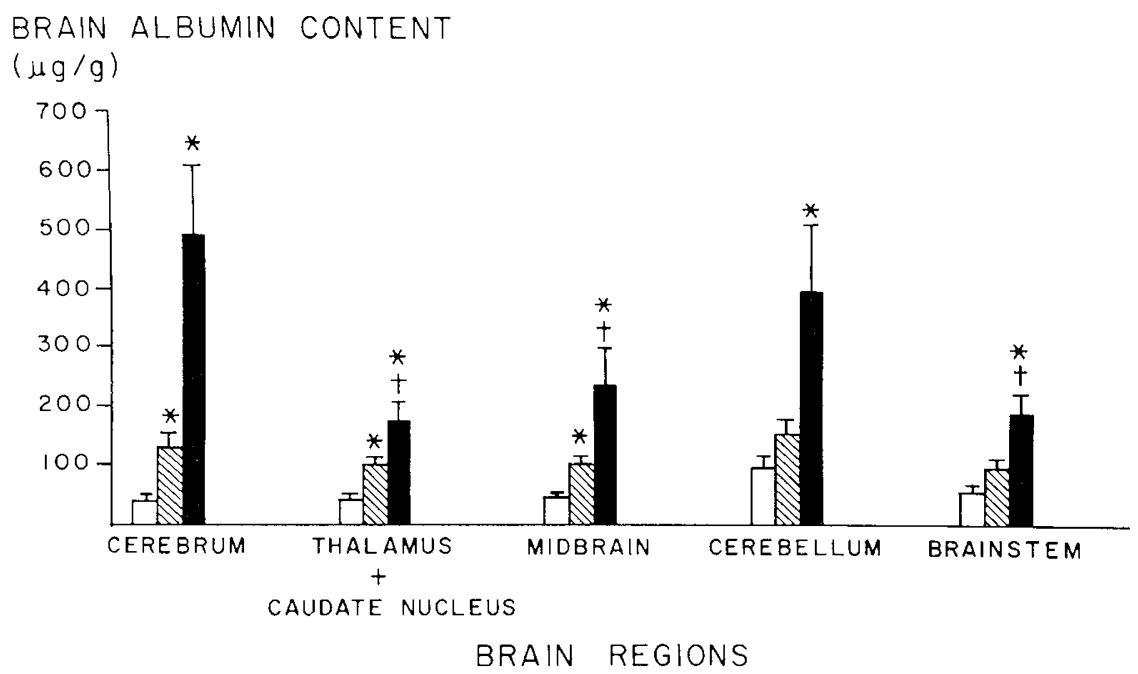

Fig. 3. Regional brain albumin content. Group legends are the same as in Figure 1. All values are expressed as mean \pm SEM. $+p<0.05$ as compared to the cerebrum value within the same group. ${ }^{*} p<0.05$ as compared to control.

increase in blood volume occurred because of a high osmolal gradient between the extravascular and intravascular spaces. This may have resulted in 1) an initial increase in blood flow to the lungs followed by 2) an osmotic diuresis. In support of this premise, we did observe 1) significant increases in $\mathrm{PACO}_{2}$ values and decreases in $\mathrm{pH}$ values following the urea infusion in both experimental groups and 2) increasing hematocrit values in association with the increased urine output in E2 animals.

The infusion of human serum albumin (contained within the bilirubin solution) was tolerated well by all piglets and most likely caused the increases in the serum albumin values observed in all groups. This infusion probably did not contribute to the brain albumin concentrations observed between the groups because all groups received similar amounts of serum albumin.

The urea bolus infusion was successful in increasing the serum osmolality. However, the effect of urea on the albumin binding of bilirubin in vivo is unknown. A slow isomerization of urea into ammonium cyanate has been observed when urea is mixed with water (18). Thus, cyanate may have carbamylated albumin and this may have affected the high affinity bilirubin binding sites on albumin. The 2 -fold increase in serum unbound bilirubin found in the E2 group may be explained in part, by a urea (cyanate) effect on the bilirubin binding capacity of the piglets' albumin. The in vitro results shown in our methods section support this contention. However, the serum unbound bilirubin values in the E2 group were elevated prior to urea administration. This may partly be explained by the lower initial serum albumin levels seen in the E2 animals.

The increase in cerebral blood flow following the urea infusions cannot be explained from our data. However, we speculate that the increased intravascular volume following the urea infusion may have increased blood flow to the cerebrum. Similar increases were not seen in other brain regions, perhaps reflecting differences in the capillary surface area among the regions of the brain (1).

It has been demonstrated in rats that under normal resting conditions approximately $50 \%$ of regional brain capillaries are perfused. During stress (asphyxia) the number of perfused capillaries increases up to $95 \%$ (19). Assuming that the intravascular volume increased acutely in our animals following urea infusion, perhaps the slight increases in brain albumin concentration seen in the E1 group after urea instillation reflected the perfusion of 


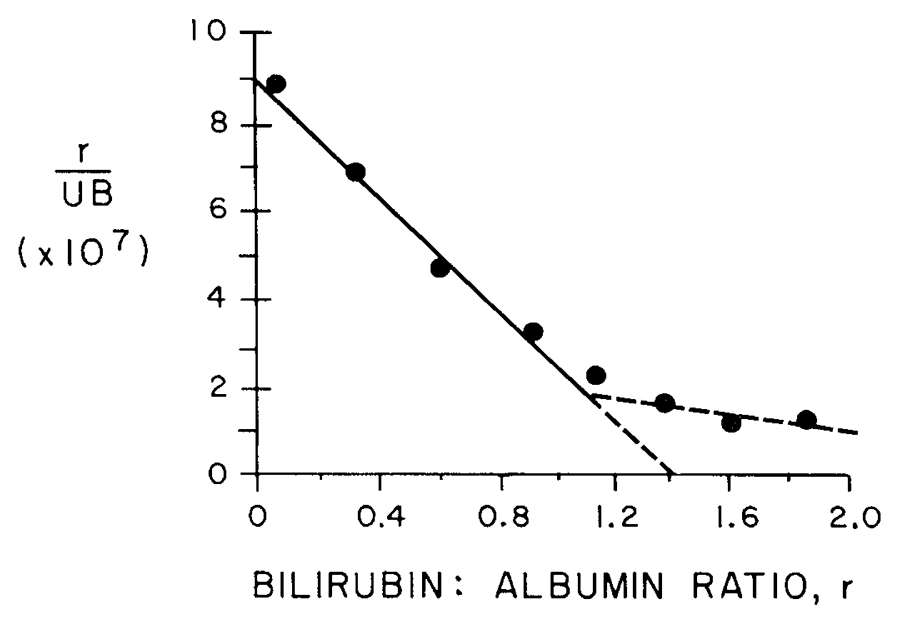

Fig. 4. Scatchard plot of binding data from one representative piglet, obtained by titration of baseline serum with bilirubin additions as shown. The plot shows that $1 \mathrm{~mol}$ of albumin binds $1.3 \mathrm{~mol}$ of bilirubin with high affinity. $r$, bilirubin albumin molar ratio; $U B$, unbound bilirubin concentration.

more capillaries (allowing for more capillary endothelial coating of albumin). Brain albumin concentrations were increased in all regions in E2 animals and regional differences were demonstrated; the thalamus plus caudate nucleus, midbrain, and brain stem levels were significantly lower than cerebrum and cerebellar levels. Regional differences in the breakdown of the blood brain barrier have previously been demonstrated in agreement with these results (19).

To characterize the form of bilirubin entering the brain, we measured the bilirubin albumin molar ratio in newborn piglets. Considering, as shown in Figure 4 , that the binding characteristics of piglet serum albumin are similar to human albumin (1 mol of albumin binds $1.3 \mathrm{~mol}$ of bilirubin) only $30-60 \%$ of the regional bilirubin seen in E2 animals are accountable by bound bilirubin. Thus, we conclude that both bound and unbound bilirubin crossed the blood brain barrier during the period of hyperosmolality $(375 \mathrm{mosmol} / \mathrm{liter})$. The increase in regional brain bilirubin concentration seen in the high hyperosmolality piglets ( $375 \mathrm{mosmol} / \mathrm{liter}$ ), and not in the $325 \mathrm{mosmol} / \mathrm{liter}$ group, is consistent with previous work in our laboratory. In rats we demonstrated a dose relationship between the level of hyperosmolality and the brain bilirubin and albumin concentrations (8). We were unable to correlate brain bilirubin concentrations and brain albumin levels in the current study of piglets, possibly because of the significant differences in serum unbound bilirubin values in the two species.

Acknowledgments. The authors acknowledge the excellent technical assistance of Mr. William Macomber, Ms. Carol Calista, and Mr. Steve Warburton. We also thank Freda Volpe for preparation of this manuscript.

\section{REFERENCES}

1. Bradbury M 1979 Regional differences in blood-interstitial fluid exchange throughout the nervous system. In: The Concept of a Blood-Brain Barrier John Wiley and Sons, Ltd, New York, pp 116-125

2. Rapaport SI, Hori M, Klatzo I 1972 Testing of a hypothesis for osmotic opening of the blood-brain barrier. Am J Physiol 223:323-331

3. Rapaport SI, Ohno K, Fredericks WR, Pettigrew KD 1978 Regional cerebrovascular permeability to $\left[{ }^{14} \mathrm{C}\right]$ sucrose after osmotic opening of the bloodbrain barrier. Brain Res 150:653-657

4. Laas R, Helmke K 1981 Regional cerebral blood flow following unilateral blood-brain barrier alteration induced by hyperosmolar perfusion in the albino rat. In: Cerebral Microcirculation and Metabolism. Cervós-Navarro J, Fritschka E (eds) Raven Press, New York, pp 317-321

5. Wahl, M., Kuschinsky W, Bosse O, Thurau K 1973 Dependency of pial arterial and arteriolar diameter on perivascular osmolarity in the cat. Circ Res 32:162-169

6. Burgess GH, Oh W, Bratlid D, Brubakk AM, Cashore WJ, Stonestreet BS The effects of brain blood flow on brain bilirubin deposition in newborn piglets. Pediatr Res (in press)

7. Levine RL, Fredericks WR, Rapaport SI 1982 Entry of bilirubin into the brain due to the opening of the blood-brain barrier. Pediatrics 69: 255-259

8. Bratlid D, Cashore WJ, Oh W 1983 Effect of serum hyperosmolality on opening of blood-brain barrier for bilirubin in rat brain. Pediatrics 71: 909-912

9. Broderson R, Bartels P 1969 Enzymatic oxidation of bilirubin. Eur J Biochem 10: $468-473$

10. Heymann MA, Payne BD, Hoffman JIE, Rudolph AM 1977 Blood flow measurements with radionuclide-labeled particles. Prog Cardiovasc Dis 20: $55-79$

11. Bratlid D, Winsnes A 1971 Determination of conjugated and unconjugated bilirubin methods based on direct spectrophotometry and chloroform extraction. A reappraisal. Scand J Clin Lab Invest 28: 41-48

12. Martinek, RG 1966 Improved micromethod for determination of serum bilirubin. Clin Chem Acta 13:161-170

13. Jacobsen J, Wennberg RP 1974 Determination of unbound bilirubin in serum of newborns. Clin Chem 20: 783-789

14. Doumas BT, Watson WA, Biggs HG 1971 Albumin Standards and the measurement of serum albumin with bromcresol green. Clin Chem Acta 31: 8796

15. Dunnett CW 1964 New tables for multiple comparisons with a control. Biometrics 20:482-491

16. Wallenstein, S, Zucker CL, Fleiss JL 1980 Some statistical methods useful in circulation research. Circ Res 47: 1-9

17. Hansen NB, Brubakk AM, Bratlid D, Oh W, Stonestreet BS 1984 The effects of variations in $\mathrm{PaCO}_{2}$ on brain blood flow and cardiac output in the newborn piglet. Pediatr Res 18: 1132-1136

18. Dirnhuber P, Schutz F 1948 The isomeric transformation of urea into ammonium cyanate in aqueous solutions. Biochem J 42: 628-632

19. Weiss, HR, Buchweitz E, Murtha TJ, Auletta M 1982 Quantitative regional determination of morphometric indices of the total and perfused capillary network in the rat brain. Circ Res 51: 494-503 